\title{
Assessment of treatment effects on digital ulcer and blood perfusion by laser speckle contrast analysis in a patient affected by systemic sclerosis
}

\author{
B. Ruaro, S. Paolino, C. Pizzorni, M. Cutolo, A. Sulli
}

Research Laboratory and Academic Division of Clinical Rheumatology, Department of Internal Medicine, University of Genova, IRCCS Ospedale Policlinico San Martino, Genoa, Italy

\section{SUMMARY}

Laser speckle contrast analysis (LASCA) is a good tool to evaluate the variation in peripheral blood perfusion during long-term follow-up and is able to safely monitor digital ulcer evolution in scleroderma patients. It evaluates blood perfusion in different areas within the skin lesions and surrounding them during standard treatment.

Key words: Systemic sclerosis, LASCA, blood perfusion

\section{RADIOLOGICAL VIGNETTE}

A 57 year-old female (M.E.) presented to our Rheumatology Outpatient Service in February 2012, with a digital periungual ulcer on her third left finger, severe Raynaud's phenomenon and joint pain that had been affecting her hand and wrists for a two-year period. Her condition had previously been controlled by her GP with painkillers. She was an ex-smoker and, in 2011, had a traumatic fracture of the second finger of her left hand.

Physical examination evidenced a periungual ulcer on her third left fingertip, puffy fingers, Raynaud's phenomenon, initial sclerodactily and facial telangiectasia. She also had a swollen right wrist and some painful metacarpophalangeal joints.

Laboratory tests revealed positive antinuclear antibodies (titre 1:640, with a homogeneous and nucleolar indirect immunefluorescence pattern) and facial telangiectasia. Blood tests evidenced a rise in the inflammatory markers: erythrocyte sedimentation rate, C-reactive protein and gamma globulin protein percentage $(54 \mathrm{~mm} / 1 \mathrm{~h}$, $10 \mathrm{mg} / \mathrm{L}$, and $21 \%$ respectively). More- over, there was a slight consumption of $\mathrm{C} 3$ complement fraction $(0.84 \mathrm{~g} / \mathrm{L})$. The other laboratory tests, which included renal and liver function tests, rheumatoid factor and anti-citrullinated protein antibodies, were unremarkable. Nailfold videocapillaroscopy (NVC) was performed to evaluate Raynaud's phenomenon (1-4). The NVC examination demonstrated a sclerodermapattern, characterized by an early pattern of microangiopathy, with a few giant capillaries, a few capillary haemorrhages and a relatively well-preserved capillary distribution, without evident capillary loss (Figure 1A) (5-7).

In 2012 a diagnosis of systemic sclerosis (SSc) was made according to the LeRoy 2001 criteria (8). Disease severity was assessed by several instrumental examinations: chest X-ray, spirometry, oesophageal manometry, which were all within the normal range, renal Doppler echography that showed normal renal artery resistive indexes, and heart echography that showed no pathological findings; estimated sPAP was $27 \mathrm{mmHg}$.

Treatment was planned with iloprost (continuous 5-day intravenous infusion), 
bosentan (65 mg twice daily which was increased after one month to $125 \mathrm{mg}$ twice daily), methotrexate (10 mg/week) and analgesic drugs (tramadol $50 \mathrm{mg} /$ day) (9-10). Before starting the pharmacological treatment, laser speckle contrast analysis (LASCA) was performed to evaluate both the extension and perfusion of the ulcer area (Figure 2A) (11-14).

Her symptoms gradually improved over a two-month period, with progressive normalization of the inflammatory markers. Her digital ulcer made progressive recovery and her skin blood perfusion increased, as evidenced by a control LASCA examination (Figure 2B).

During a follow-up visit in 2014 , the patient had an increase in renal artery resistive indexes and was started on ramipril at $5 \mathrm{mg} /$ day. In 2015, her NVC switched to an active pattern of microangiopathy with frequent giant capillaries, frequent capillary haemorrhages and a moderate capillary loss (Figures 1B) (5-7). The patient had no new digital ulcers.

The patient was put on cyclic intravenous iloprost for Raynaud's phenomenon, but in 2016, she was no longer able to continue the therapy prescribed due to problems at her workplace. Therefore, aminaphtone (75 mg twice daily) was started off-label, in combination with her other treatment (bosentan, methotrexate and ramipril).

Raynaud condition score, frequency and duration of Raynaud's attacks and LASCA were performed at baseline (T0) and after four (T4) weeks of treatment, at the level of her hands to evaluate her clinical condition (Figure 3). Treatment with aminaphtone improved the symptoms related to Raynaud's phenomenon, and the blood perfusion in all skin areas improved rapidly (Figure 3, T4).

At time of writing the NVC status and organ involvement have not changed since 2015 and the patient has had no new digital ulcers since 2013.

Acknowledgements and Funding: the authors would like to thank Barbara Wade, contract Professor at the University of Torino, for her linguistic advice. Dr. Sara De

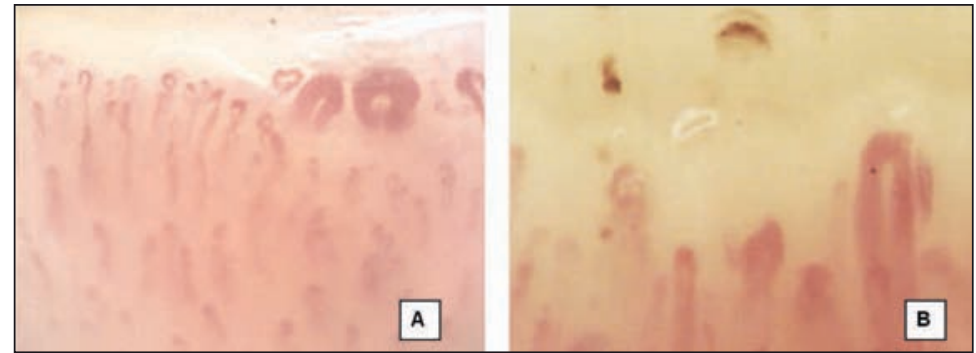

Figure 1 - Nailfoild videocapillaroscopic patterns of scleroderma microangiopathy (200x) in our patient (ME), showing an Early pattern in 2012 (A), and an Active pattern in 2015 (B).

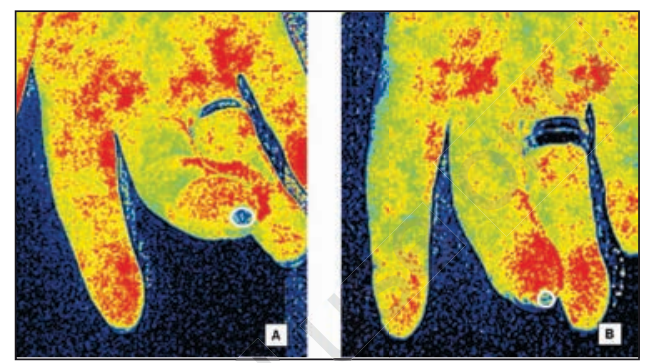

Figure 2 - LASCA images ( $3^{\text {rd }}$ finger) of active ulcer before $(A)$ and after two months' treatment $(B)$, at the fingertip level. Scan image: blue $=$ low blood perfusion (BP), yellow = intermediate $\mathrm{BP}$, red $=$ high $\mathrm{BP}$.
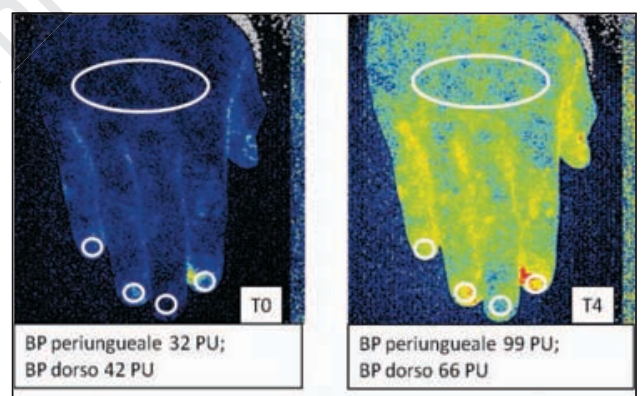

$\mathrm{BP}$ dorso $42 \mathrm{PU}$

$\mathrm{BP}$ dorso $66 \mathrm{PU}$

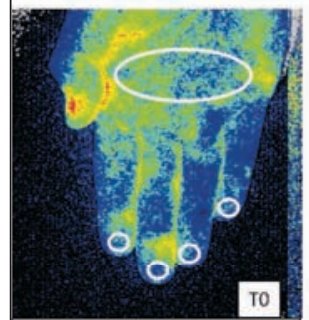

BP polpastrello $40 \mathrm{PU}$ BP palmo $50 \mathrm{PU}$

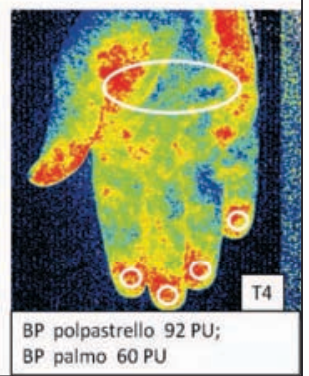

Figure 3 - LASCA images of the dorsum and palm of the hand in our SSc patients before (T0) and at four weeks (T4) of treatment with Aminapthone. Perfusion is reported as perfusion units $(\mathrm{PU}) . \mathrm{BP}=$ blood perfusion. 
Gregorio from the Division of Rheumatology, University of Genova, supported the graphic reproduction. Teresa Cannavale, Health Professional of Rheumatology, performed DU medications. Barbara Ruaro is supported by a Grant from the Italian Society of Rheumatology, obtained in 2015. All the authors are members of the EULAR Study Group on Microcirculation in Rheumatic Diseases.

Conflict of interest: Maurizio Cutolo received research grants from Actelion, BMS, Laboratori Baldacci and SanofiAventis.

\section{REFERENCES}

1. Zeni S, Ingegnoli F. Raynaud's phenomenon. Reumatismo. 2004; 56: 77-81.

2. Lubatti C, Ingegnoli F, Gualtierotti R, et al. Nailfold capillaroscopic report: qualitative and quantitative methods. Reumatismo. 2008; 60: 249-53.

3. Cutolo M, Pizzorni C, Meroni M, et al. The role of nailfold videocapillaroscopy in Raynaud's phenomenon monitoring and early diagnosis of systemic sclerosis. Reumatismo. 2010; 62: 237-47.

4. Bernero E, Sulli A, Ferrari G, et al. Prospective capillaroscopy-based study on transition from primary to secondary Raynaud's phenomenon: preliminary results. Reumatismo. 2013; 65: 186-91.

5. Cutolo M, Sulli A, Pizzorni C, Accardo S. Nailfold videocapillaroscopy assessment of microvascular damage in systemic sclerosis. J Rheumatol. 2000; 27: 155-60.

6. Cutolo M, Pizzorni C, Tuccio M, et al. Nailfold videocapillaroscopic patterns and serum autoantibodies in systemic sclerosis. Rheumatology (Oxford). 2004; 43: 719-26.

7. Sulli A, Secchi ME, Pizzorni C, Cutolo M. Scoring the nailfold microvascular changes during the capillaroscopic analysis in systemic sclerosis patients. Ann Rheum Dis. 2008; 67: 885-7.

8. LeRoy EC, Medsger TA Jr. Criteria for the classification of early systemic sclerosis. J Rheumatol. 2001; 28: 1573-6.

9. Catarsi E, Doveri M, Tavoni A. Bosentan and sildenafil: successful treatment in a sclerodermic patient with refractory ulcers. Reumatismo. 2013; 65: 79-81.

10. Casigliani Rabl S, Della Rossa A, Pepe P, et al. Long-term cyclic intravenous iloprost in systemic sclerosis: clinical experience from a single center. Reumatismo. 2012; 64: 158-65.

11. Ruaro B, Sulli A, Alessandri E, et al. Laser speckle contrast analysis: a new method to evaluate peripheral blood perfusion in systemic sclerosis patients. Ann Rheum Dis. 2014; 73: 1181-5.

12. Sulli A, Ruaro B, Cutolo M. Evaluation of blood perfusion by laser speckle contrast analysis in different areas of hands and face in patients with systemic sclerosis. Ann Rheum Dis. 2014; 73: 2059-61.

13. Ruaro B, Sulli A, Smith V, et al. Short-term follow-up of digital ulcers by laser speckle contrast analysis in systemic sclerosis patients. Microvasc Res. 2015; 101:82-5.

14. Ruaro B, Sulli A, Pizzorni C, et al. Correlation between skin blood perfusion values and nailfold capillaroscopy scores in systemic sclerosis patients. Microvasc Res. 2016; 105: 119-24. 